\title{
Battling the malaria iceberg with chloroquine in India Vinod P Sharma
}

\author{
Address: Centre for Rural Development and Technology, Indian Institute of Technology, Hauz Khas, New Delhi-110016, India \\ Email: Vinod P Sharma - vinodpsharma@gmail.com
}

Published: 7 August 2007

Malaria Journal 2007, 6:105 doi:10.1 186/1475-2875-6-105

This article is available from: http://www.malariajournal.com/content/6/I/105

(C) 2007 Sharma; licensee BioMed Central Ltd.

This is an Open Access article distributed under the terms of the Creative Commons Attribution License (http://creativecommons.org/licenses/by/2.0), which permits unrestricted use, distribution, and reproduction in any medium, provided the original work is properly cited.
Received: 16 November 2006

Accepted: 7 August 2007

\begin{abstract}
The National Vector Borne Disease Control Programme (NVBDCP) of the Ministry of Health, Government of India is reporting about 2 million parasite positive cases each year, although case incidence is $\mathbf{3 0}$-fold or more under-estimated. Forty five to fifty percent of Plasmodium infections are caused by Plasmodium falciparum, the killer parasite. Anti-malaria drug policy (2007) of the NVBDC recommends chloroquine (CQ) as the first line of drug for the treatment of all malarias. In a Primary Health Centre (PHC) reporting $10 \%$ or more cases of $\mathrm{CQ}$ resistance in $P$. falciparum, ACT blister pack is recommended and, so far, the policy has been adopted in 26I PHCs of 7I districts. The NVBDCP still depends on CQ to combat malaria and, as a result, $P$. falciparum has taken deep roots in malaria-endemic regions, causing unacceptable levels of morbidity and mortality. This policy was a subject of criticism in recent Nature and Lancet articles questioning the World Bank's decision to supply $\mathrm{CQ}$ to the NVBDCP. Continuation of an outdated drug in the treatment of $P$. falciparum is counterproductive in fighting drug resistant malaria and in the containment of $P$. falciparum. Switchover to Artemisinin-based Combination Therapy (ACT) in the treatment of all $P$. falciparum cases, ban on artemisinin monotherapy and effective vector control (treated nets/efficient insecticide spraying) would be a rational approach to malaria control in India.
\end{abstract}

\section{Background}

The National Vector Borne Disease Control Programme (NVBDCP) is reporting about 2 million parasite positive cases a year, $50 \%$ of these Plasmodium falciparum. The WHO estimates 100 million cases in the South East Asian Region, $70 \%$ of these occur in India [1,2]. Independent studies by the Indian Council of Medical Research have unequivocally established that malaria incidence is hugely under-estimated [3-6]. Health is the state's responsibility, therefore, malaria control is carried out by the states, under the overall guidance of the NVBDCP. To monitor the impact of interventions surveillance is organized to detect malaria cases by examining fever cases in the entire country. In rural areas, blood smears are collected at fortnightly intervals by multi-purpose workers i.e. through Active Case Detection (ACD) and also collected at the Primary Health Centres (PHCs) i.e. Passive Case Detection (PCD). In urban areas, PCD is carried out at the malaria clinics. The blood smears are examined in the laboratory for parasite identification and results are used for follow-up action. Cases found positive are given radical treatment, as per the policy of the NVBDCP. This data is used in calculating epidemiological indices at the various levels of health services. PHCs reporting cases of drug failure are referred to the drug monitoring teams for further investigation on drug sensitivity in $P$. falciparum. If $25 \%$ (now reduced to $10 \%$ ) of the cases tested show resistance to $C Q$, the drug policy is changed for the second line of drug. Thirteen NVBDCP teams routinely monitor $P$. falciparum drug sensitivity in the country. These teams are located in various regions so as to cover the entire country. $P$. falciparum monitoring for drug sensitivity is done using 
the World Health Organization (WHO) methodology of in vivo (28-day) test procedure for determining the status of resistance to CQ and other antimalarial drugs in $P$. falciparum. Malaria Drug Policy (2007) of the NVBDCP provides inter alia the following treatment guidelines countrywide [7].

1. All fever cases should preferably be investigated for malaria by microscopy or Rapid Detection Test (RDT).

2. The first line of treatment is chloroquine and the second line is ACT (artesunate+sulphadoxine/pyrimethamine) combination in case resistant to these formulations and to treat severe and complicated malaria, quinine will be the drug of choice.

3. Microscopically positive $P$. falciparum cases should be treated with chloroquine in therapeutic dose of $25 \mathrm{mg} / \mathrm{kg}$ body weight over three days and a single dose of primaquine $0,75 \mathrm{mg} / \mathrm{kg}$ body weight on the first day. The practice is to be followed at all levels including Voluntary Health Workers (VHWs) like Drug Distribution Centres (DDCs)/Fever Treatment Depots(FTDs)/Accredited Social Health Activist (ASHA) as well.

The antimalarial drug policy states that all Plasmodium vivax cases, undiagnosed fever cases, and clinical malaria cases should be treated with chloroquine in full therapeutic doses. ACT (artesunate+sulphadoxine/pyrimethamine) is the first line of antimalarial drug for treatment of $P$. falciparum in chloroquine resistant areas. Chloroquine, therefore, remains the main drug for the treatment of all malarias in India except in PHCs with $10 \%$ or more cases found resistant to it. The objective of this paper is to highlight the realistic and evidence-based malaria situation in the country, and how the changes in drug policy and efficient vector control can wipe out malaria, thus bringing out the importance of the WHO recommendation of a switch over to artemisinin-based fixed-dose combination therapy (ACT) to treat all $P$. falciparum cases (sensitive or resistant to $\mathrm{CQ} / \mathrm{SP}$ ).

\section{Discussion}

Studies on re-emergence of malaria revealed countrywide presence and spread of $P$. falciparum e.g. $P$. falciparum is found in all states and union territories except Lakshadweep Island (Malaria situation 2002-2006, NVBDCP). It may be noted that $P$. falciparum occurrence is highly uneven in time and space $[8,9]$. Furthermore, the NVBDCP is reporting malaria epidemics in five or six states each year, and frequent focal outbreaks [10]. In some parts of the country, malaria epidemics cover two or more districts, dominated by $P$. falciparum [11-14]. Currently an epidemic of malaria is raging in Assam, a region more frequently visited by annual exacerbations $[15,16]$. The country-wide presence of $P$. falciparum is facilitated by inter- and intra-state population movement, particularly for civil works, agriculture, rail road construction, rural urban migration; thus providing opportunities for the mutant strains to disseminate across district and state boundaries [17-19].

It is important to highlight the resilience of $P$. falciparum in India. During the early years of malaria resurgence [20], a focus of $P$. falciparum and detection of CQ resistant foci in Karbi-Anglong district in Assam [21] in the north-eastern states required steps for its containment and prevention of its spread to the mainland. Therefore, a special drive was launched under the P. falciparum Containment Programme (PfCP), financed by the Swedish International Development Agency (SIDA). PfCP was first launched in 1978 in 18 high $P$. falciparum districts in the north-eastern states, gradually extended to 55 districts (311 PHCs in 14 states) and in 1982 to 110 districts (1410 PHCs in 18 states). Despite of PfCP operations that heavily depended on Dichloro-Diphenyl-Trichloroethane (DDT) and Chloroquine (CQ), P. falciparum occupied larger territories and covered the entire county's transmission belts and remained firm. The purpose and the strategy of PfCP was defeated and PfCP was terminated in 1988 [22]. Epidemiological investigations revealed that $P$. falciparum was replacing $P$. vivax in central India [23]. It is noteworthy to mention that decadal $P$. falciparum rise has been substantial, an increase of $120 \%$ since the first resurgence decade (1971-80). P. falciparum is rising slowly but steadily [24] over these decades as shown in Figure 1.

Malaria epidemiology and its control are complicated by poverty as it is a dominant disease in poverty stricken societies. For example, Indian states with population exceeding the national average of $26.1 \%$ population below poverty line (BPL) contributed $88 \%$ P. falciparum in 2000 [25]. Addressing the plenary session of United Nations Conference on Human Environment at Stockholm,14 June 1972, the former Prime Minister of India Smt. Indira Gandhi said "Are not poverty and need the greatest polluters? [26] Poverty alleviation is on the national and United Nations agenda. How to fight poverty which is at the roots of all ills? Certainly malaria control is an important tool to alleviate human suffering caused by poverty and ill health. Therefore, priorities in malaria control should remain high, national and international bodies should work in tandem to eradicate this age old "King of all Diseases".

Plasmodium falciparum monitoring for drug sensitivity is conducted by thirteen NVBDCP teams. Monitoring is done on the line of WHO methodology of in vivo (28-day) standard techniques for determination of resistance in $P$ falciparum to CQ and other antimalarials. India is a vast 


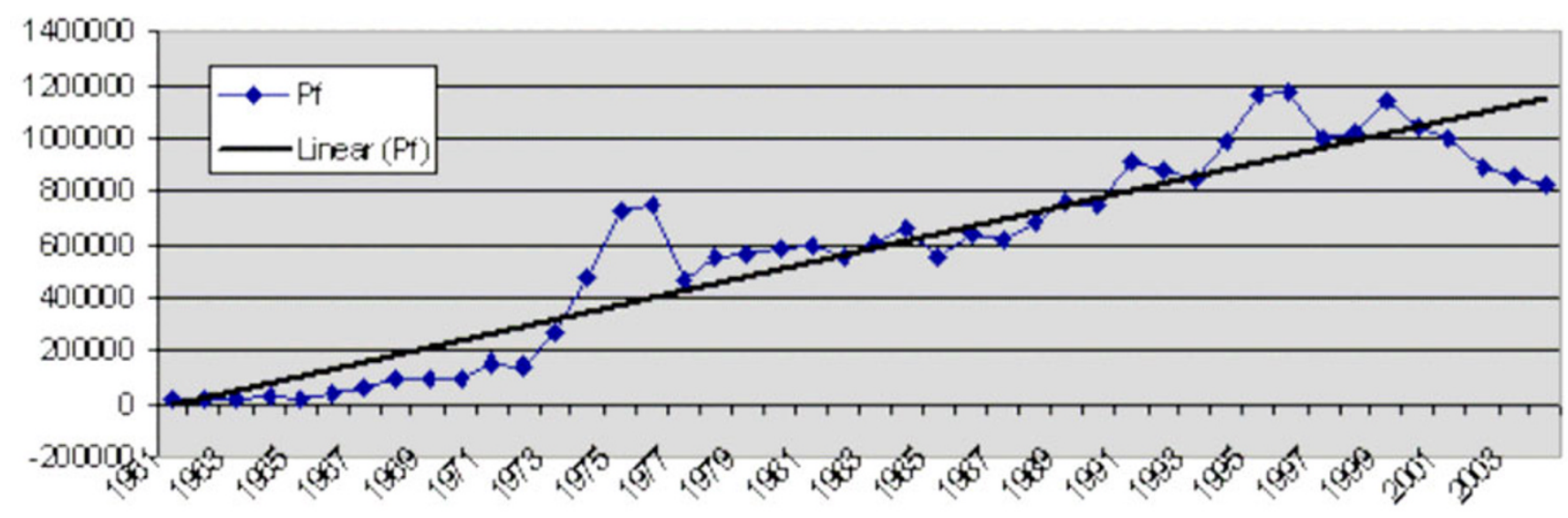

Figure I

P. falciparum cases in India (I96I-2004).

country, so it is difficult to generalize. However, between 1978 and June 2001, a total of 15,069 P. falciparum cases in 178 districts of 28 states and union territories have been completed. Of these 3,965 (26.3\%) were sensitive to CQ; 7,661 (50.8) were S/RI; 2,142 RI resistant; 752 RII resistant (5\%) and 549 (3.6\%) RIII resistant to CQ [27]. In 2004, the $P$. falciparum monitoring teams collected 45,966 blood smears, of which 4,756 were positive for malaria and 3,850 for $P$. falciparum (80.95\%). Results based on CQ sensitivity of 209 samples, showed Adequate Clinical and Parasitological Response (ACPR) 98 (47.9\%), Early Treatment Failure (ETF) 27 (12.9\%) and Late Treatment Failure (LTF) 84 (40.2\%). Drug resistance to CQ is presenting countrywide, although proportion of resistant strains varies greatly [28-33]. Already the Pfcrt K76T mutation, an important determinant of CQ resistance, is present in $>95 \%$ of $P$. falciparum isolates [34]. In addition to these clear indicators of resistance in the parasite populations, there are important changes in disease outcomes. For example, in patients with $P$. falciparum infections, acute renal and multi-organ failures have almost doubled in the last 5-7 years. Although it is not possible to attribute this directly to the decreasing efficacy of CQ, but it may be an important factor, as it has been in malaria-related deaths in African children [35]. The deteriorating trends in $P$. falciparum demands urgent radical changes in antimalarial drug policy. ACT is currently used in 261 PHCs (71 districts) as against approximately 14,000 malaria endemic PHCs. The process of adoption to ACT is painfully slow and may take a long time, until then CQ remains the first line drug in India. In 2006 a series of articles in The Lancet [36-38] and Nature [39] concerned funding of antimalaria drugs by the World Bank. The Lancet paper criticized the World Bank for funding the purchase of CQ by the Indian government. There is substantial evidence that CQ is no longer effective against $P$. falciparum in many areas of India, and under those circumstances the purchase of CQ supports a dangerous public health practice. One response to the criticism was that CQ is used in India only to combat P. vivax, a species against which it is mostly still effective. This statement contradicts the drug policy of the NVBDCP which recommends the use of $\mathrm{CQ}$ to treat all malaria cases, including P. falciparum, the more lethal pathogen.

It may be underscored that malaria situation in India is worsening due to ineffective vector control largely the result of DDT spraying [40] and the poor choice of antimalarials, for example India's CQ consumption in 1976 was 61 metric tons $(\mathrm{mt})$ to treat 6.45 million cases (the highest since resurgence) and, in 2005, cases have been reduced by $70 \%$, but CQ consumption has increased ten times [41]. Table 1 illustrates one example among many, of the impact of inefficient spraying and increasing dependence on CQ. In Betul district, Madhya Pradesh, a malaria epidemic was building-up due to inefficient and inadequate DDT spraying and the decreasing effectiveness of CQ. Thus, the CQ use increased enormously with no signs of epidemic abatement. Several measures were required to finally control the epidemic: a switch from DDT to synthetic pyrethroid (SP) indoor residual spraying, introduction of larvivorous Gambusia (Gambusia affinis) and Guppy (Poecilia reticulata) fishes, and on-spot diagnosis to cover all households was initiated. Then with correct diagnosis, only P. vivax was treated with CQ; $P$. falciparum was treated with sulfadoxine-pyrimethamine $(P$. falciparum was susceptible to it). With these changes, the district was nearly malaria free by 2005 [42].

The WHO recommends fixed dose artemisinin combination therapy for $P$. falciparum [43]. In light of the clear evidence for CQ-resistance in $P$. falciparum, and the 
Table I: Malaria in Betul District, Madhya Pradesh, India

\begin{tabular}{|c|c|c|c|c|c|c|}
\hline Year & $\begin{array}{c}\text { DDT (50\% WP) sprayed } \\
\text { in mt against } 200 \mathrm{mt} \\
\text { required }\end{array}$ & $\begin{array}{l}\text { Synthetic Pyrethroid } \\
\text { sprayed in } \mathrm{mt}\end{array}$ & $\begin{array}{l}\text { CQ Tablets } \\
\text { (150 mg base) }\end{array}$ & $\begin{array}{l}\text { Fansidar } \\
\text { Tablets }\end{array}$ & $\begin{array}{l}\text { Total malaria } \\
\text { cases }\end{array}$ & $\begin{array}{l}\text { P. falciparum } \\
\text { cases }\end{array}$ \\
\hline 1990 & Nil & Nil & & Nil & 496 & 91 \\
\hline 1991 & $\mathrm{Nil}$ & Nil & & $\mathrm{Nil}$ & 949 & 281 \\
\hline 1992 & 4.00 & Nil & $5,00,000$ & Nil & 805 & 196 \\
\hline 1993 & 1.60 & $\mathrm{Nil}$ & $5,10,000$ & $\mathrm{Nil}$ & 626 & 213 \\
\hline 1994 & 4.90 & Nil & $5,40,000$ & Nil & $\mathrm{I}, 503$ & 602 \\
\hline 1995 & 2.30 & Nil & $6,20,000$ & Nil & 1,820 & 739 \\
\hline 1996 & 7.40 & Nil & $7,70,000$ & $\mathrm{Nil}$ & 2,290 & 662 \\
\hline 1997 & 9.90 & Nil & $9,80,000$ & $\mathrm{Nil}$ & 5,279 & 1,764 \\
\hline 1998 & 14,90 & Nil & $9,60,000$ & Nil & 8,872 & 3,340 \\
\hline 1999 & 10.20 & Nil & $13,88,000$ & $\mathrm{Nil}$ & 14,133 & 3,919 \\
\hline 2000 & 18.0 & Nil & $20,30,000$ & Nil & 16,764 & 7,126 \\
\hline 2001 & Nil & 4698.4 & $36,83,000$ & 49,520 & 18,440 & 7,398 \\
\hline 2002 & $\mathrm{Nil}$ & 3512.9 & $25,33.000$ & 59,094 & 4,911 & 992 \\
\hline 2003 & $\mathrm{Nil}$ & 6429.8 & $29,82,000$ & 45,400 & 1,080 & 168 \\
\hline 2004 & Nil & 2528.8 & $16,28,000$ & 4,600 & 1,063 & 855 \\
\hline 2005 & Nil & 1352.0 & $12,22,000$ & 2,740 & 373 & 193 \\
\hline
\end{tabular}

Source: District Malaria Officer, Betul district M.P.

recommendation for using CQ as the treatment for all malaria, not just $P$. vivax, the NVBDCP should respond to the recommendation of the Lancet Viewpoint and abandon CQ, in favour of ACT. Indian states with high prevalence of $P$. falciparum have the problem of CQ resistance, although the proportion remains undetermined. CQ and sulphadoxine/pyrimethanine (SP) resistance is more pronounced in the north-eastern states and Orissa. Multidrug-resistant strains abound on the international borders with the Indian NE states [44-46]. Artesunate with SP combination (blister pack) is now recommended in drug resistant areas. In seven states in the northeastern region of the country, ACT is being introduced in one district in each state in the pilot phase. Further expansion would depend on the experience gained in the districts in northeastern region. This switch over to ACT would take place in 71 districts in the country (261 PHCs, but there are approximately 14,000 high risk PHCs requiring ACT to treat $P$. falciparum), with provision to expand this coverage to adjacent PHCs reporting $>10 \%$ CQ resistant $P$. falciparum. States have been advised to monitor the status of drug resistance in the adjacent PHCs for the expansion of ACT. PHCs lacking microscopic facility would be supplied with rapid diagnostic test kits to detect $P$. falciparum. Furthermore, artemisinin drugs are frequently used as monotherapy in the private sector, the racket of substandard and fake drugs [47], private sector working in isolation, government support to herbal drugs failing in scientific scrutiny [48] and indiscretion in the use of artemisinin are dangerous signals, and failure to address these problems may endanger life of patients and accelerate resistance. Thus the inertia may open the possibility of an epicenter of drug resistant malaria in South East Asia. Finally, with- holding correct malaria treatment for unfounded reasons, lacking sound scientific basis and wise clinical judgment, is both unethical and discriminatory. Malaria is predominantly the disease of the poor lacking health equity. This inequity should be leveled by following correct drugs and drug schedule to the needy and unprotected for a relentless war against malaria. Setting the house in order is a formidable challenge. Therefore, inter alia policy issues must be addressed by the NVBDCP first and the foremost.

\section{Acknowledgements}

We are grateful to Dr Neeru Singh, Sr Dy Director, Regional Medical Research Centre for Tribals, Jabalpur, M.P. for providing useful inputs in the preparation of this manuscript.

\section{References}

I. WHO: First meeting of the Regional Technical Advisory Group on Malaria, Manesar, Haryana, India 15-I 7 December 2004 World Health Organization, Regional Office for South-East Asia, New Delhi SEA-MAL239:1-38.

2. WHO: Strategic Plan to Roll Back Malaria in the South-East Asia Region World Health Organization, Regional Office for South-East Asia, New Delhi SEA-MAL- 237:I-25.

3. Snow RW, Guerra CA, Noor AM, Myint HY, Hay SI: The global distribution of clinical episodes of Plasmodium falciparum malaria. Nature 2005, 434:214-217.

4. Choudhury DS, Malhotra MS, Shukla RP, Ghosh SK, Sharma VP: Resurgence of malaria in Gadarpur PHC district Nainital, Uttar Pradesh. Indian J Malariol 1983, 20:49-58.

5. Yadav RS, Bhatt RM, Kohli VK, Sharma VP: The burden of malaria in Ahmedabad city, India - a retrospective analysis of reported cases and deaths. Ann Trop Med Parasit 2003, 97:793-802.

6. Sharma VP, Choudhury DS, Ansari MA, Malhotra MS, Menon PKB, Razdan RK, Batra CP: Studies on the true incidence of malaria in Kharkhoda (Distt. Sonepat, Haryana) and Kichha (distt. Nainital, U.P.) Primary Health Centers. Indian J Malariol I983, 20:2I-34.

7. NVBDCP: Malaria Drug Policy 2007 [http://www.nvdcp.gov.in/Dod Revised $\% 20$ drug\%20 policy.pdf]. 
8. Sharma VP, Mehrotra KN: Malaria resurgence in India : A critical study. Soc Sci Med 1986, 22:835-845.

9. Sharma VP: Re-emergence of malaria in India. Indian J Med Res 1996, 103:26-45.

10. Malaria epidemics/outbreaks [http://www.searo.who.int/EN/ Section $10 /$ Section2I/Section $1987 . \mathrm{htm}]$

II. Raghavendra K, Subbarao SK, Sharma VP: An investigation in to the recent malaria outbreak of malaria in district Gurgaon, Haryana state. Curr Sci 1997, 73:766-770.

12. Neeru Singh, Shukla MM, Chand SK, Sharma VP: Outbreak of falciparum malaria in submerged villages of Narayanganj PHC district Mandla due to Narmada irrigation project, Central India, Madhya Pradesh. Curr Sci 1997, 73:686-69I.

13. Neeru Singh, Sharma VP, Shukla MM, Gyan Chand: Malaria outbreak in Kundam block, district Jabalpur, M.P. Indian J Malariol 1988, 25:41-49.

14. Singh Neeru, Shukla MM, Sharma VP, Saxena BN: A focus of high degree chloroquine resistant $\boldsymbol{P}$ falciparum in Mandla District (M.P.). Indian J Malariol 1989, 26:45-5I.

15. Malaria epidemic kills $\mathbf{5 0}$ in Assam

[http://in.news.yahoo.com/0604/8/43/63m3w.html]

16. Dev V, Sharma VP: Persistent transmission of malaria in Sonapur PHC Kamrup district Assam. J Parasitol Dis 1995 19:65-68.

17. Kumar A, Sharma VP, Thavaselvam D: Malaria related to constructions in Panaji, Goa. Indian I Malariol I99|, 28:219-226.

18. Adak T, Batra CP, Mittal PK, Sharma VP: Malaria outbreak in a hotel construction site in South Delhi. Indian J Malariol 1994, 31:|26-|3|.

19. Sharma RC, Sharma VP: Epidemiological implications of population migration: Part II Evidence of chloroquine resistant Plasmodium falciparum malaria in Kheda district Gujarat. Indian J Malariol 1988, 25:17-II8.

20. Sharma VP: Current scenario of malaria in India. Parassitologia 1999, 41:349-353.

21. Sehgal PN, Sharma MID, Gogai S: Resistance to chloroquine in falciparum malaria in Assam State, India. J Comm Dis 1973, 5:175-180

22. Ray AP, Narasimham MVVL, Kondrashin AV, Anna-Kari Bill: $P$. falciparum containment programme. Ten years of operation in India (1978-1988). PfCP/Directorate of NMEP/WHO/SIDA, Delhi; 1998.

23. Singh Neeru, Nagpal AC, Saxena Ajay, Singh MP: Changing scenario of malaria in central India, the replacement of Plasmodium vivax by Plasmodium falciparum( 1986-2000). Trop Med Int Health 2004, 9:364-37I.

24. India Malaria Profile [http://www.searo.who.int/LinkFiles/Malaria Profile India.pdf

25. Sharma VP: Malaria and poverty in India. Curr Sci 2003, 84:5।3-5|5.

26. Department of Environment, Government of India: Indira Gandhi on Environment. 1984:1-123.

27. Malaria Drug Policy. Unpublished document. NVBDCP, 22-Sham Nath Marg Delhi-I I0054

28. Singh N, Tyagi AK, Sharma VP: Drug resistant Plasmodium falciparum in Mandla district, Madhya Pradesh. Indian J Malariol 1995, 32:174-177.

29. Ghosh SK, Choudhury DS, Chandrahas RK, Singh Neeru, Ramanaiah TV, Sharma VP: Drug resistant $P$. falciparum in Madras (Tamil Nadu) and District Jabalpur (Madhya Pradesh). Indian J Malariol 1989, 26:87-90.

30. Sinha S, Dua VK, Sharma VP: Chloroquine resistant imported $P$. falciparum in an industrial complex at Hardwar. Indian J Malariol 1989, 26:123-125.

31. Dua VK, Kar PK, Gupta NC, Kar I, Sharma VP: In vivo and in vitro sensitivity of Plasmodium falciparum to chloroquine in Chennai (Tamil Nadu), India. Indian I Malariol 1997, 34:1-7.

32. Ghosh SK, Yadav RS, Sharma VP: Sensitivity status of Plasmodium falciparum to chloroquine, amodiaquine, quinine, mefloquine and sulfadoxine/pyrimethamine in a tribal population of district Sundergarh, Orissa. Indian J Malariol 1992, 29:2 II-2I8.

33. Sinha S, Choudhury DS, Ghosh SK, Usha Devi C, Sharma VP: In vitro Chloroquine resistant Plasmodium falciparum in Calcutta and its sensitivity in Qinghaosu (Artemisinin). Indian J Malariol 1987, 24:107-110.
34. Vathsala PG, Pramanik A, Dhanasekaran S, UshaDevi C, Pillai CR, Subbarao SK, Ghosh SK, Tiwari SN, Sathyanarayan TS, Deshpande PR, Mishra GC, Ranjit MR, Dash AP, Rangarajan PN, Padmanaban G: Widespread occurrence of the Plasmodium falciparum chloroquine resistance transporter (Pfcrt) gene haplotype SVMNT in P falciparum malaria in India. Am J Trop Med Hyg 2004, 70:256-259.

35. Snow RW, Trape JF, Marsh K: The past, present and future of childhood malaria mortality in Africa. Trends Parasitol 200I, I7:593-597.

36. Time for the World Bank to act on malaria. The Lancet 2006, 367:1372.

37. Attaran A, Barnes K, Bate R, Binka F, d'Allessandro U, Fanello C, Garrett $\mathrm{Cl}$, Mutabingwa $\mathrm{L}$, Roberts TK, D Sibley $\mathrm{CH}$, Talisuna $\mathrm{A}$, van Geertruyden JP, Watkins WM: The World Bank: fake financial and statistical accounts and medical malpractice in malaria treatment. The Lancet 2006, 368:247-252.

38. Sarbib JL, Nankarni G, Patel P: The booster program for malaria control: putting knowledge and money to work. The Lancet 2006, 368:253-257.

39. World Bank defends efforts to curb malaria. Nature 2006, 440: 1096-1097.

40. Sharma VP: DDT: The fallen angel. Curr Sci 2003, 85: I532-1537.

41. Sharma VP: Artemisinin drugs in the treatment of $P$. falciparum malaria in India. Curr Sci 90:1323-1324

42. Sharma VP: Malaria in Betul submitted to the Government of Madhya Pradesh, (Unpublished work). Tour report 2006.

43. World Health Organization: FACTS and ACTS (Artemisinin based combination therapies). FACTS ON ACTS (Artemisinin-based combination therapies), Geneva

[http://www.google.co.in/ search?hl=en\&q=WHO+FACTS+and+ACTs\&btnG=Google+Search \&meta]. January 2006 update

44. Mohapatra PK, Prakash A, Bhattacharya DR, Goswami BK, Mahanata $\mathrm{J}$ : Concurrent multidrug resistant Plasmodium falciparum from northeast India. J Assoc Phys India 1999, 47(8):823-824.

45. Mohapatra PK, Prakash A, Taison K, Negmu K, Gohain AC, Namchoom NS, Wange D, Bhattacharya DR, Goswami BK, Borgohain BK, Mahanata J: Evaluation of chloroquine (CQ) and sulphadoxine pyrimethamine (SP) therapy in uncomplicated falciparum malaria in Indo-Myanmar border areas. Trop Med Int Health 2005, 10:478-483.

46. Mohapatra PK, Namchoom NS, Prakash A, Bhattacharya DR, Goswami BK, Mahanata J: Therapeutic efficacy of anti-malarials in Plasmodium falciparum malaria in an Indo-Myanmar border area of Arunachal Pradesh. Indian J Med Res 2003, I I 8:7I-76.

47. South-east Asia awash with fake drugs [http://www.guardian.co.uk/international/story/0,2018238,00.html]

48. Valecha N, Usha Devi C, Joshi Hema, Sahi VK, Sharma VP, Lal Shiv : Comparative efficacy of Ayush-64 vs. chloroquine in vivax malaria. Curr Sci 2000, 78: I I20-II 22.

Publish with Bio Med Central and every scientist can read your work free of charge

"BioMed Central will be the most significant development for disseminating the results of biomedical research in our lifetime. "

Sir Paul Nurse, Cancer Research UK

Your research papers will be:

- available free of charge to the entire biomedical community

- peer reviewed and published immediately upon acceptance

- cited in PubMed and archived on PubMed Central

- yours - you keep the copyright
BioMedcentral 